\title{
Los compañeros del viaje del migrante
}

\author{
Victoria Núñez Navarro*
}

Si acaso las fronteras se engendran en el seno de lo apenas comprensible de las probetas del interés político, económico y social; si acaso estas fronteras se reproducen con los custodiados bálsamos de la convicción sobre lo correcto, lo conveniente, lo necesario e inevitable en pro de un orden mundial; si acaso el control es factible al amparo de condiciones que se fortalecen a la sombra de un derecho, que más que defender juzga y condena al que transita por desiertos y ríos, al que se encarama a la bestia, y al que la bestia le mata o le amputa las ganas de caminar o de vivir... si acaso tal vez es el momento de que conozcamos unas historias que a veces van y que a veces vienen.

\section{¿Por qué me lo pregunta?}

Sí, yo salí de mi pueblo porque no teníamos que comer, ni que sembrar, nos daba mucha hambre... No, no, no tenemos tierra. Mi amá nos hacía un caldo con agua de un arroyo mugroso y unas ramas que arrancaba de la tierra... Ni sé que eran, no le pregunté, nadie le preguntaba, capaz de que no nos daba nada de tragar. Hace tres años que no veo a mis hermanos ni a mi amá... jes bien enojona! Mi apá se fue hace mucho, dizque a trabajar, pero nunca volvió. Nos quedamos mis seis hermanos, mi amá y mi tata. Mi tata yo creo que le llega a los noventa años, creo. Contaba muchas historias, pero ya no... yo creo que no tiene fuerzas, está flaco, flaco como mi amá y mis hermanos. Mi amá siempre está muina, nos daba nuestros buenos chingazos a cada rato, con la mano, con una vara, con cualquier palo que se encontraba. A uno de mis carnalitos una vez le sacó la sangre del espinazo. Todos corríamos, pero nos los guardaba, no se le olvidaba a la doñita... Ya se ve viejita, pero no se deja... Creo que tiene 48 años... ¿por qué?

Yo fui el único que fue a la escuela, estaba muy lejos, pero fui dos años, creo que me gustaba, pero después mi amá ya no me dejó ir porque decía que era muy burro.

\footnotetext{
* MTC del Departamento de Trabajo Social de la Universidad de Sonora, victorian@sociales.uson.mx
}

Yo salí de allá en el tren con el Ramón... es mi primo. Yo y él nos vinimos hace tres años. Él tenía un amigo que se fue a un lugar que se llama "Finiz", pallá vamos.

Yo nunca me había subido y cuando ya estábamos arriba del techo me dijo que le decían la bestia... Sí me dio miedo cuando me subí, éramos un chingo y luego, a cada rato se subían más y más. Eso sí me dio harto miedo. A cada rato me empujaban a la orilla, sentía que me iba a caer, no había de dónde agarrarse. No... no pensé en bajarme... ¿por qué?

Mucho calor, mucho sol, mucha hambre, mucha sed. Nos llovió y me dio mucho frío, mojado y con el viento. Hacíamos nuestras necesidades ahí arriba, era un cochinero. Para los hombres era más fácil, pero las mujeres se hacían en su ropa.

No, no, a mí no me hicieron nada en el camino... bueno nomás me arrebataron el lonche que mi amá me había dado. No sé de dónde lo sacó, a lo mejor le dio gusto que me fuera porque consiguió tortillas y frijoles... Sí, eran cinco tacos de frijoles, pero me los arrebataron cuando apenas me iba subiendo... Sí... nomás eso me pasó. Bueno, a un amigo de mi primo lo agarraron... arriba del tren... sí.

No le robaron, creo que le hicieron otra cosa... pues ya sabe... se lo cog... sí, creo que lo agarraron entre muchos. Se puso a gritar como puerco atorado, pero nadie le hizo caso, fue en la noche y todos se hacían los dormidos. Sí, muchas noches pasaba lo mismo, lo agarraron de su puerquito, a él y a otra morra que iba con su hijo en el rebozo, los dos estaban chille y chille. A mí no me pasó eso... a mí no... ¿por qué?

También me acuerdo del Juan, ya venía en el tren cuando nos subimos, hablaba curado. Él nos dijo que no nos acercáramos a las orillas ni que brincáramos entre los vagones, que era muy peligroso. Nos platicó que era la tercera vez que viajaba así, dos veces lo devolvieron y otra vez lo metieron dos años a una cárcel, no entendí dónde ni por qué no lo dejaron salir. Dijo que nos avisaría cuándo agarrarnos fuerte, bajar por un lado del vagón y estirarnos para arrancar de las manos de unas doñitas, comida y agua sin que el tren se detuviera. Era güilo, güilo, pero ya sabía defenderse. Traía

\section{Savía}




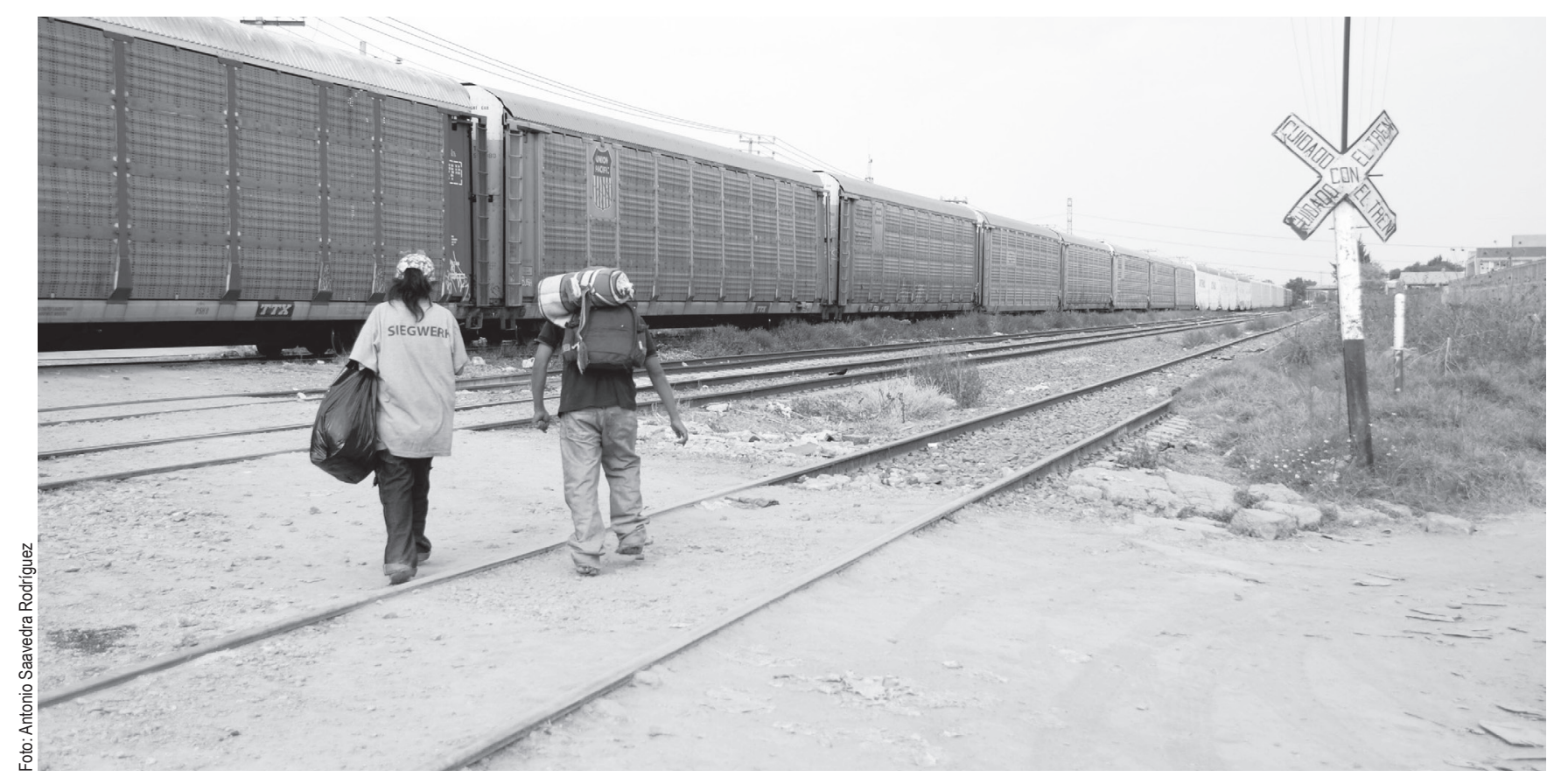

un machete con tres marcas en el mango, dijo que eran tres cristianos que se los había echado porque querían robarle sus zapatos y el machete. Un día, no sé cómo, se acercó mucho a la orilla y se resbaló a la chingada... se cayó y lo agarró el tren... El Ramón se asomó y vio que estaba tirado en un charco de sangre sin una pierna... sin machete y sin zapato. No, el tren no se paró... No... ¿por qué?

Yo creo que pronto me largo a "Finiz" porque yo ya pensé, el coyote pide mucho, mejor me lanzo yo solo, no me pasa nada. El Ramón ya se arrejuntó con una morra que trabaja en una casa, viven con los suegros y ya está panzona... no creo que se vaya... no creo que lo dejen.

Además, me dijo el Ramón que va a sacar una tarjeta, es la "IFEN" y que con esa puede sacar otra para pasar y la migra no nos puede detener. Si no me lanzo solo saco la "IFEN" y luego la otra para pasar... eso si antes no empanzono a una morra aquí. Tengo 15 años... ¿por qué?

El hambre migra, no cabe duda. La indefensión migra, la violación a los elementales derechos humanos migra también. El analfabetismo migra, la violencia migra. En la bestia o no, los motivos para alejarse del terruño y de su gente, se esconden cual criminales al acecho, listos para atacar y defender su existencia a perpetuidad, independientemente del lugar y del tiempo. Son los compañeros de su viaje. El daño está hecho.

Realmente el origen y el destino es lo de menos, lo importante aquí es que las mujeres, hombres, niños, personas de la tercera edad llevan de equipaje sus tristezas, preocupaciones, desesperaciones, deterioros y vidas conflictuadas por años. Vicisitudes ancestrales que difícilmente desaparecerán. Es ficticio el duelo momentáneo de una separación durante una travesía cruenta, pues llevan ya tiempo en las trampas de la pobreza o en los campos minados por conflictos bélicos o por cuestiones del narcotráfico; ya el deterioro físico y psicológico difícilmente desaparecerá de su vida. Es decir, a las condiciones existentes al momento de embarque, se suma la incertidumbre y el temor a lo desconocido.

Más allá del análisis de una o más fronteras, contigüidad física o de las facilidades y dificultades para trasladarse y permanecer, es menester realizar una reflexión sobre el respeto a un entramado de formas de sentir, pensar, saber y hacer en espacios de simetrías y asimetrías donde se percibe la presencia de luchas y búsquedas de grupos humanos en pos del poder que otorga la posesión parcial o total de un territorio y de sus respectivos recursos.

En un contexto diverso de capital económico, cultural, social y hasta genético, el planeta entero cuenta con criterios concretos, específicos que arrojan luz sobre las condiciones de vida de sus habitantes; si bien, la dimensión cuantitativa se dificulta y el apego a la veracidad y confiabilidad de los datos duros es hasta cierto punto laxo, existen los indicadores universales que potencian el diseño exprofeso de estrategias de atención a sectores vulnerables en claras vías hacia la migración. La migración como destino es identificable y prevenible a partir, por ejemplo, del análisis de indicadores manejados por instancias oficiales cuya labor es la observancia y registro de información sobre aristas relativas a los ingresos, salud, educación, vivienda, seguridad social, etcétera.

La propuesta es por un lado reforzar la atención multi e interdisciplinaria al hoy del migrante, al análisis de su situación, de sus vicisitudes y a la toma de decisiones que incidan en el potencial escenario futuro en el que se encontrará en corto, mediano y largo plazo.

Por otro lado y en forma simultánea, reforzar, diseñar, ejecutar y evaluar estrategias que se traduzcan en la mejora de condiciones de vida en los lugares de origen del probable sector susceptible de convertirse en migrante. 